\title{
DIMENSIONAMENTO DE SISTEMAS EÓLICOS NO ENTORNO GEOGRÁFICO DO MUNICÍPIO DE MARECHAL CÂNDIDO RONDON ${ }^{1}$
}

\author{
Carolina Sayury Miyashiro², Eliana Suzi Wakassugui ${ }^{3}$, Kenia Gabriela dos Santos ${ }^{4}$, Carlos H. Coimbra-Araújo ${ }^{5}$ \\ 1 Aceito para publicação, $2^{\circ}$ trimestre de 2013. \\ 2 Acadêmica do curso de Tecnologia em biocombustíveis UFPR - Setor Palotina. \\ 3 Acadêmica do curso de Tecnologia em biocombustíveis UFPR - Setor Palotina. \\ ${ }^{4}$ Acadêmica do curso de Tecnologia em biocombustíveis UFPR - Setor Palotina. \\ ${ }^{5}$ Doutor em Física. Mestre em Astronomia, Professor da Universidade Federal do Paraná - Setor Palotina.
}

Palavras-chave: Energia Eólica, Energia Limpa.

\section{Resumo}

A crescente preocupação em torno das questões ambientais e devido aos impactos causados pelas formas tradicionais de geração de energia advindas de fontes fósseis, vários países vêm investindo na introdução de fontes alternativas de energia. Vários setores da sociedade brasileira notaram a necessidade do uso racional e diversificação das fontes de energia elétrica. O desenvolvimento da energia eólica dentro do Brasil tem se destacado como geração complementar de energia limpa. Desta forma, para a instalação de parques eólicos, é interessante observar as características meteorológicas do local de instalação e equipamentos para que a eficiência energética do sistema seja a melhor possível. Com o intuito de instalar um projeto de turbina eólica na cidade de Marechal Candido Rondon buscou-se dados literários para se obter os valores característicos do local como altitude e velocidade dos ventos. A partir desses dados foi possível avaliar o potencial eólico de 3 cenários e em cada um deles foi avaliada o quanto de energia pode ser gerada em $\mathrm{kWh} / \mathrm{mês}$. Com os resultados obtidos foi estudada a hipótese de suporte para uma residência de pequeno porte com o gasto total mensal de $330 \mathrm{kWh} / \mathrm{mês}$. No presente trabalho, não obtivemos uma boa viabilidade, devido ao teor dos ventos de Marechal Candido Rondon ser muito baixo atingindo no máximo 55,2 KWh/mês, necessitando de no mínimo 6 turbinas para sustentar a residência 


\section{Introdução}

A principal fonte energética mundial na atualidade advém de combustíveis fósseis, o que contribui para uma elevada dependência energética. No entanto, atualmente vê-se o forte desenvolvimento gradual de países motivados por maiores anseios por independência energética, investindo em alternativas que tendem a minimizar a geração dos gases de efeito estufa (GEE), impulsionando o estudo e desenvolvimento de energias renováveis.

Vários governos estão traçando novas estratégias de fornecimento de energia elétrica a curto e a longo prazos devido à preocupação com o aumento do consumo de eletricidade nos últimos anos. Esta preocupação justifica um planejamento mais eficaz e rigoroso para essas estratégias, de forma a suprir as necessidades da população. Nesse contexto são encontrados fontes de energia abundante que atualmente são pouco exploradas para geração de energia elétrica, como a energia solar, eólica, das marés.

Desta forma, a energia gerada pelos ventos é uma alternativa para a geração de energia, pois é considerada uma abundante fonte de energia renovável, limpa e disponível em vários lugares, que pode ser obtida pela energia cinética contida nas massas de ar em movimento (NIPO, 2007). A utilização dessa energia tem sido aplicada a vários anos, e foi uma das primeiras formas energéticas de tração não animal utilizada pelo homem para mover os barcos, impulsionados por velas. Nos moinhos de vento a energia eólica era transformada em energia mecânica, utilizada na moagem de grãos e bombeamento de água.

A experiência dos países líderes do setor de geração eólica mostra que o rápido desenvolvimento da tecnologia e do mercado têm aplicações socioeconômicas. A formação de recursos humanos e a pesquisa científica recebem incentivos com a finalidade de fornecer suporte necessário para a indústria de energia eólica em formação. Na atualidade, diversos estudos apontam a geração de emprego e o domínio da tecnologia como fatores tão importantes quanto à preservação ambiental.

Novos investimentos em infraestrutura na área de energia renováveis nos países em desenvolvimento e industrializados visam promover a segurança energética e a criação de oportunidades para que se alcancem reduções de emissões de gases de efeito estufa. Os benefícios adicionais obtidos são específicos de cada país, mas envolvem, com frequiência, a redução da poluição do ar, melhoria da balança comercial, fornecimento de serviços modernos de energia nas áreas rurais e geração de empregos (IPCC, 2007).

O Brasil é um país que encontra-se em uma situação favorável para a utilização de energias renováveis. Atualmente, $80 \%$ da geração de eletricidade no país é proveniente de 
meios hídricos. Contudo, esta fonte energética é preocupante devido a diminuição da disponibilidade de locais para grandes obras hidroelétricas. Como resultado, há distâncias cada vez maiores até os centros de consumo, degradação do meio ambiente por inundações e linhas de transmissão, e custos cada vez maiores para a sociedade (MARRANGHELLO, 2004).

Para que a geração de eletricidade a partir do movimento do ar seja possível e atraente, tanto técnica quanto economicamente, alguns fatores são determinantes. $\mathrm{O}$ valor da energia produzida varia com o cubo da velocidade dos ventos, o que significa que a potência de saída é altamente sensível a este fator: um aumento de $10 \%$ no mesmo acarreta em $33 \%$ a mais de energia disponível.

No Brasil, a capacidade instalada ainda é muito pequena quando comparada aos países líderes em geração eólica. No entanto, políticas de incentivos estão começando a produzir os primeiros resultados e espera-se um crescimento da exploração deste recurso nos próximos anos (SANTOS et al. 2006). No entanto, nem todas as regiões brasileiras tem potencial eólico e neste sentido, o presente trabalho realiza um estudo de caso para um município da região oeste do Paraná (Marechal Cândido Rondon), dimensionando uma turbina e o quanto de energia esta produz quando instalada em algum local do entorno geográfico do município.

\section{APLICAÇÃO DOS VENTOS}

Uma aplicação que vem se destacando é o aproveitamento de tecnologias relativamente recentes para a energia eólica como fonte alternativa de energia para produção de eletricidade. Em seu livro, Gasch e Twele [12] detalham a evolução da tecnologia da energia eólica desde seu emprego em moinhos de vento a partir de 1700 a.C. até os modernos aerogeradores de eletricidade. Estudos para conversão da energia cinética dos ventos em eletricidade vêm sendo desenvolvidos nos últimos anos.

Os sistemas de conversão à energia eólica exploram a energia contida na movimentação das massas de ar atmosféricas que são causadas pelo aquecimento da superfície terrestre pelos raios solares. Eles aproveitam a energia cinética dos ventos para movimentar turbinas eólicas que por sua vez movimentarão os geradores de energia. Após sua instalação, apresentam um grande benefício no setor econômico além de diminuir impactos na flora e na fauna que são causados devido a utilização de recursos fósseis. 
Desde o início da década de 1990 o setor de energia eólica vem apresentando um crescimento acelerado em todo o mundo. A capacidade instalada total mundial de aerogeradores voltados à produção de energia elétrica atingiu 74223 MW ao final de 2006, apresentando um crescimento de mais de $20 \%$ em relação a 2005. Segundo o Global Wind Energy Council (2006), este crescimento de capacidade instalada ao longo de 2006 representa o maior acréscimo observado ao longo de um ano.

\section{ENERGIA EÓLICA NO SETOR BRASILEIRO}

O Brasil é considerado o $12^{\circ}$ maior consumidor de energia do mundo, com um nível de consumo equiparado ao da Itália e da Espanha. Aquele país ainda apresenta um grande atraso em relação à distribuição das fontes de geração de energia, se considerarmos as fontes renováveis, havendo uma concentração de mais de 50\%, nos estados do Sul e Sudeste, dos empreendimentos de geração de energia. Atualmente, os leilões para oferta de energia têm privilegiado a aquisição de termoelétricas, desfavorecendo a aquisição de fontes renováveis de energia elétrica, em especial a eólica, que tem grande potencial no setor brasileiro (MOREIRA).

Um marco importante para o setor elétrico brasileiro ocorreu em 2002, com a aprovação da lei 10.438, revisada pela lei 10.762 em 2003, que criou o Programa de Incentivo às Fontes Alternativas de Energia Elétrica - PROINFA (PROINFA, 2004), estabelecendo a obrigação das concessionárias de energia elétrica de participarem da universalização do acesso a esse programa. O PROINFA tem por objetivo aumentar a participação das energias alternativas no sistema interligado e diversificar a matriz energética brasileira. A compra dessa energia deverá ser feita por intermédio de licitação pública e os contratos de fornecimento assinados com a ELETROBRAS por 20 anos. Além disso, existe financiamento de até $70 \%$ do valor do investimento, com recursos disponibilizados pelo BNDES (GONÇALVES, 2007).

A análise dos dados de vento de vários locais no Nordeste confirmou as características dos existentes na região, velocidades médias de vento altas, pouca variação nas direções do vento e pouca turbulência durante todo o ano. Por isso tem se voltado grande atenção ao estado do Ceará, por ter sido um dos primeiros locais a realizar um programa de levantamento do potencial de energia eólica através de medidas de vento com modernos sensores especiais, e em outras regiões do nordeste as usinas que predominam são as térmicas, o que representam um risco ambiental. Entretanto, não foi apenas na costa do Nordeste que 
áreas de grande potencial eólico foram identificadas. Em Minas Gerais, uma central de energia eólica está em funcionamento, desde 1994, em um local (afastado mais de $1000 \mathrm{~km}$ da costa), com excelentes condições de vento.

\section{MÉTODOLOGIA}

\section{APROVEITAMENTO DE TURBINAS EÓLICAS}

A definição de um local para implantação de uma fazenda eólica requer um processo longo para avaliação de todos os condicionantes que determinam qual o melhor ponto. Devem ser considerados, além do potencial eólico promissor, o espaço disponível para instalação da fazenda eólica, preço da terra, distância em relação à rede onde a energia pode ser injetada, acessibilidade, condições para a montagem das turbinas de infra-estrutura na região, custos de manutenção, remuneração pela energia produzida. Este tipo de empreendimento requer necessariamente, análises que considerem longas séries de registros de dados de vento, além de pelo menos um ano de medidas no exato local da futura instalação (OCÁCIA, 2002).

Com o intuito de avaliar o potencial eólico de Marechal Candido Rondon, localizado no Oeste do Paraná. Pesquisou-se a velocidade média do vento, correspondendo a $20 \mathrm{~m} / \mathrm{s}$. A partir de dados de eficiência do fabricante e com as seguintes especificações da turbina com: diâmetro das pás de 3,72 metros e altura do eixo (torre) de 60 metros.

Para se obter a densidade da cidade de Marechal Candido Rondon foram pesquisados alguns dados como a altitude de 420 metros do nível do mar. Os efeitos da densidade do ar muda conforme eventos climatológicos para isso foram calculados a partir da equação (1).

$\frac{\partial p}{1,2 p}=-\frac{g \cdot M}{R \cdot T} \int \partial h$

$\partial p=1_{s} 2 \mathrm{Kg} / \mathrm{m}^{3}$

Equação (1)

Onde:

$\mathrm{g}=9,8 \mathrm{~m} / \mathrm{s}^{2}$

$\mathrm{M}=29 \mathrm{~g} / \mathrm{mol}-1$

$\mathrm{R}=8,3 \mathrm{~m}^{2} \mathrm{~J} / \mathrm{k}$ mol-1

$\mathrm{T}=22,5^{\circ} \mathrm{C}(295,5 \mathrm{~K})$ 
$\mathrm{p}=1,2 \mathrm{~kg} / \mathrm{m}^{3}$

\section{VENTOS E CIRCULAÇÃO ATMOSFÉRICA}

O vento, como agente meteorológico, atua nas modificações das condições do tempo, sendo responsável pelo transporte de umidade e de energia na atmosfera. A energia dos ventos pode provocar grande destruição quando associado a eventos como furacões e tornados. Contudo, o vento pode ser empregado como uma fonte alternativa de energia por meio da conversão de sua energia cinética em outras formas de energia.

Os ventos que sopram em escala global e aqueles que se manifestam em pequena escala são influenciados por diferentes aspectos entre os quais destacam-se a rugosidade do solo, os obstáculos e o relevo. As massas de ar em movimento possuem energia cinética, que pode ser aproveitada com o uso de aerogeradores, os quais têm a capacidade de converter esta energia cinética contida nos ventos em energia elétrica (SILVA, 1999; TERCIOTE, 2002).

Em torno de 1 a $2 \%$ da energia solar é convertida em energia dos ventos. As regiões onde esse tipo de conversão de energia inicia-se são nas regiões existentes na linha Equador, onde a latitude é $0^{\circ}$ e ocorre um maior aquecimento nas massas de ar e posteriormente é estendida para as regiões norte e sul do planeta (MOREIRA, ano).

Tendo em vista que as massas de ar podem se alterar com a altitude do local de instalação da turbina, estipulou-se um dado valor para um terreno onde possui plantação de soja e através de dados literários pode-se obter o fator de rugosidade. Para se calcular a velocidade do vento em dada altura utilizou-se a Equação (2).

$\mathrm{V}=v_{0} \quad\left(\frac{h}{h 0}\right)^{n}$

Equação (2)

Onde:

$\mathrm{V}=$ velocidade do vento

$\mathrm{v} 0$ = velocidade de referência;

$\mathrm{h}=$ altura da cidade mais a altura do eixo da torre

h0 $=$ altura da cidade

$\mathrm{n}=$ fator de rugosidade

Para selecionar um local para geração de energia eólica, vários fatores devem ser cuidadosamente analisados, medir intensidade, frequência e direção dos ventos no local por 
alguns anos, para se obter resultados precisos das características locais. Estas medições são feitas por empresas especializadas e com instrumentos de medição específicos. Alguns fatores de rugosidade e seus respectivos valores teóricos estão listados na Tabela 1

Tabela 1: Fatores de rugosidade

\begin{tabular}{cc}
\hline Cenário & Fator de rugosidade \\
\hline Sítio com lavoura de soja & 0,19 \\
Cidade com prédios & 0,26 \\
Áreas florestadas & 0,28 \\
\hline
\end{tabular}

Dentro desse projeto para se obter essas informações de velocidade inicial e velocidade média pesquisou-se em dados meteorológicos, as equações abaixo apresentam os resultados obtidos para velocidade potencial de cada cenário.

$V=5 . \frac{480^{0.19}}{420} \quad V=6,05 \mathrm{~m} / \mathrm{s}$

Velocidade dos ventos para cidade com prédios

$V=5 . \frac{480^{0,26}}{420} \quad V=6,48 \mathrm{~m} / \mathrm{s}$

Velocidade dos ventos para área florestada

$V=5 \cdot \frac{480^{0,28}}{420} \quad V=6,61 \mathrm{~m} / \mathrm{s}$

Se utilizou os dados de diâmetro das pás do aerogerador Skystream5 para se calcular o potencial para Marechal Candido Rondon a partir da Equação (3).

$\rho=\frac{1}{2} \rho(a r) \frac{\pi}{4} \cdot D^{2} \cdot v^{3}$

Equação (3)

Onde:

$\rho=$ Potencial dos ventos 
$\rho(\operatorname{ar})=$ densidade do ar

$\mathrm{D}^{2}=$ diâmetro das pás

$\mathrm{V}^{3}=$ velocidade do vento em cada cenário

A potência extraída dos ventos, depende da densidade do ar no local " $D$ ", do tamanho das pás e da velocidade do vento "V" elevada ao cubo. Para que a obtenção da potência eólica seja aproximada da realidade, devem-se incluir alguns conceitos de índice de aproveitamento e considerar os rendimentos dos equipamentos. Os valores de potencial de instalação estão listados na tabela 2

Tabela 2: Potencial de Instalação para Marechal Candido Rondon

\begin{tabular}{cc}
\hline Cenários & Potencial eólico $(\mathbf{w})$ \\
\hline Sitio com lavoura de soja & $1397,29(\mathrm{w})$ \\
Cidade com prédios & $1716,90(\mathrm{w})$ \\
Área florestada & $1822,32(\mathrm{w})$ \\
\hline
\end{tabular}

A turbina desvia o vento antes deste chegar ao plano do rotor, pelo que nunca será possível captar toda a energia do vento. Quanto maior for a energia cinética extraída pela turbina ao vento, mais este será travado à saída da turbina. Se teoricamente fosse possível extrair toda a energia ao vento, o ar sairia com velocidade nula, que de fato o ar não abandonaria a turbina.

Entre estes dois extremos existe um valor para o qual a conversão de energia eólica em energia mecânica é mais eficiente: uma turbina irá travar até cerca de $2 / 3$ da sua velocidade inicial. Este valor obtém-se da formulação de 1919, realizada pelo físico Albert Betz, e conhecida como Lei de Betz. De acordo com a Lei de Betz, apenas menos de 16/27 da energia cinética pode ser convertida em energia mecânica por uma turbina eólica (TERCIOTE). Na Tabela 3 estão listados os valores de eficiências mecânicas e elétrica.

Tabela 3: Eficiência elétrica e mecânica

\begin{tabular}{lllll}
\hline Eficiência elétrica & 0,40 & 0,40 & 0,80 & TOTAL \\
Eficiência mecânica & 0,95 & 0,80 & 0 & 0,10336
\end{tabular}

Para o cálculo da eficiência foram utilizados, a Equação (4) de acordo com a Lei de Betz, eficiência proposta em escala laboratorial, segundo Wenzel.

$$
P I=P x \mathrm{x} x X
$$

Equação (4) 
Onde:

$\mathrm{PI}=$ Potência Instalada

$\mathrm{P}=$ Potencial dos ventos para cada cenário

$\mathrm{D}=$ Valor total entre a eficiência elétrica e mecânica

$\mathrm{X}=$ Valor de hora/mês do funcionamento da turbina

Com o intuito de instalação de uma residência de pequeno porte em cada um dos cenários foram pesquisados dados teóricos para se obter o rendimento em $\mathrm{KWh} / \mathrm{mês}$ de uma residência de pequeno porte com eletrodomésticos essenciais foram de 330KWH/mês, que estão apresentados na Tabela (4).

Tabela 4: Potencial instalado e número de turbinas necessários para abastecer uma residência

\begin{tabular}{ccc}
\hline Cenários & $\begin{array}{c}\text { Potência Instalada } \\
(\mathbf{K w} / \mathbf{h} / \mathbf{m e ̂ s})\end{array}$ & $\begin{array}{c}\mathbf{N}^{\mathbf{0}} \text { de Turbinas para manter } \\
\text { a residência }\end{array}$ \\
\hline Sítio com lavoura de soja & $40,66(\mathrm{kw} / \mathrm{h} / \mathrm{mês})$ & 8 \\
Cidade com prédios & $50,22(\mathrm{kw} / \mathrm{h} / \mathrm{mês})$ & 6 \\
Área florestada & $53,37(\mathrm{kw} / \mathrm{h} / \mathrm{mês})$ & 6 \\
\hline
\end{tabular}

Alguns fatores podem interferir na velocidade do vento como barreiras naturais denominados árvores e plantações e construções elevadas que, quando estão na direção do vento que passa pelo aerogerador, causam uma diminuição da velocidade do vento e turbulência levando a danificação do equipamento. Esses fatores são extremamente importantes devido que este influencia diretamente no potencial eólico. Na Figura (1) podemos comparar os dados da potência instalada e do potencial eólico.

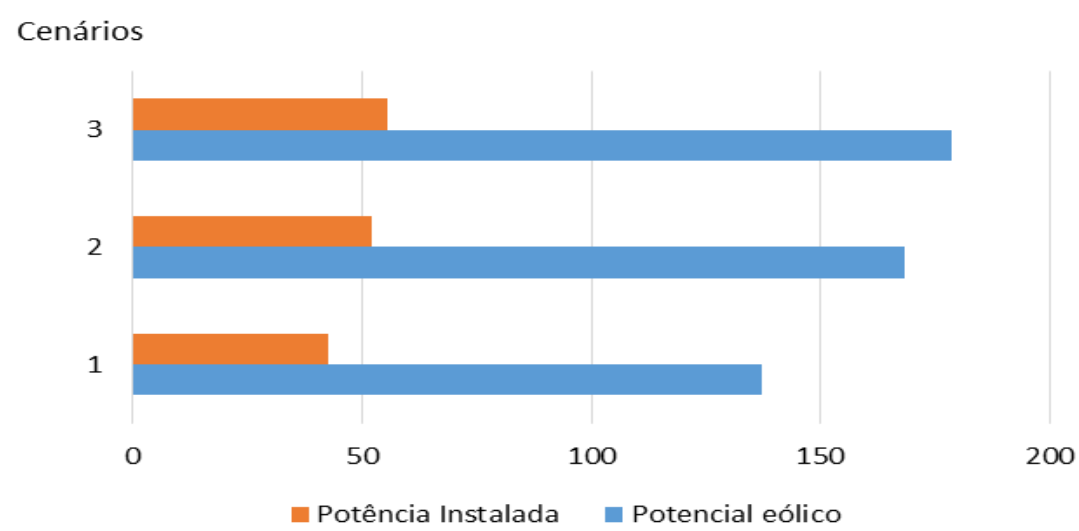

Figura 1: Apresenta potencial instalado comparado com o potencial eólico

Dentro dos estudos avaliados podemos dizer que os valores de potencial instalado para 1 turbina não atendem as condições de sustentação de uma residência de pequeno porte. 
Para se obter um potencial de instalação para sustentar a residência seria necessário uma potência eólica de aproximadamente 10.800 watts.

\section{Conclusão}

A energia eólica tem um futuro ainda mais promissor com a com scientização pública das suas vantagens como fonte renovável de energia e a progressiva competitividade econômica. As questões ambientais estão cada vez mais difundidas e atitudes em favor ao meio ambiente estão se tornando parte integrante dos processos decisórios sob vários aspectos. Pode-se acrescentar como ponto positivo, a facilidade e capacidade de implantar ou expandir as fazendas eólicas de acordo com a demanda real e sua respectiva evolução

Com o estudo do desenvolvimento do projeto de uma turbina eólica, conclui-se que para um projeto deste porte, não atingiu bons resultados entre os 3 cenários avaliados. A área que mostrar-se melhor potencial foi a área florestada apresentaram uma melhor eficiência elétrica com 55,2 (KWh/mês) mais mesmo dentro desse valor seriam necessários 6 turbinas para sustentar uma residência com gasto de $330 \mathrm{KWh} / \mathrm{mês}$. E o investimento seria inviável na questão econômica devido que 1 turbina Skystream apresenta um custo de R $\$ 31.800,00$.

São necessárias pesquisas e avanços tecnológicos para otimização na performance dos equipamentos com o objetivo de diminuir os custos relativos à manutenção e aumentar o rendimento das turbinas eólicas. Algumas questões são dependentes do avanço tecnológico de outros setores da indústria, como no caso da fabricação de materiais mais leves, baratos e resistentes e na produção de máquinas com maiores taxas de rendimento e aproveitamento de energia. 


\section{Referências}

1. ANEEL. Energia Eólica. Disponível em: 〈www.aneel.gov.br/arquivos/PDF/17-05_materia1_3.pdf〉

2. TERCIOTE, R. A Energia Eólica e o Meio Ambiente. Faculdade de Energia Mecânica, UNICAMP, Campinas SP.

3. SCHÜTZER, H. Estudo de energia eólica e pequena central hidrelétrica e simulação em conjunto na região do Ribeirão do Lobo. 81 f. Trabalho de graduação. (Engenharia Elétrica) - Universidade de São Paulo, Escola de Engenharia de São Carlos, São Paulo, 2012.

4. OLIVEIRA. F. F. T, Et al. Uso da Energia Eólica como alternativa para mitigar o agravamento do efeito estufa. - Universidade Católica de Goiás.

5. SANTOS, A. A.; Et al. Projeto de Geração de Energia Eólica, Curso DE Engenharia Industrial Mecânica. 2006.

6. SANTOS, A.A.; RAMOS, D.S.; SANTOS, N. T. F.; OLIVEIRA, P.P. Projeto de geração de energia eólica. Projeto de Graduação do Curso de Engenharia Industrial Mecânica. Universidade Santa Cecília, 2006.

7. NIPO, D.F. Controlador de carregamento de baterias para turbinas eólicas de pequeno porte. $123 \mathrm{~F}$. Tese (Doutorado em Engenharia Mecânica) - Universidade Federal de Pernambuco, Recife, 2007.

8. MONTEIRO, R. T. T. Análise de Ciclo de Vida do Biodiesel - Aplicação à Realidade Nacional, Universidade de Aveiro, 2009.

9. TAN, K. T.; GUI, M. M.; LEE, K. T.; MOHAMED, A. R. Supercritical alcohol technology in biodiesel production: A comparative study between methanol and ethanol. Energy Sources, Part A: Recovery, Utilization, and Environmental Effects, v. 33, n. 2, p. 156-163, 2010.

10. GLOBAL WIND ENERGY COUNCIL. Global Wind 2006 Report. Disponível em: < http://www.gwec.net/?id=8 > Acesso em: 15 jun. 2013 